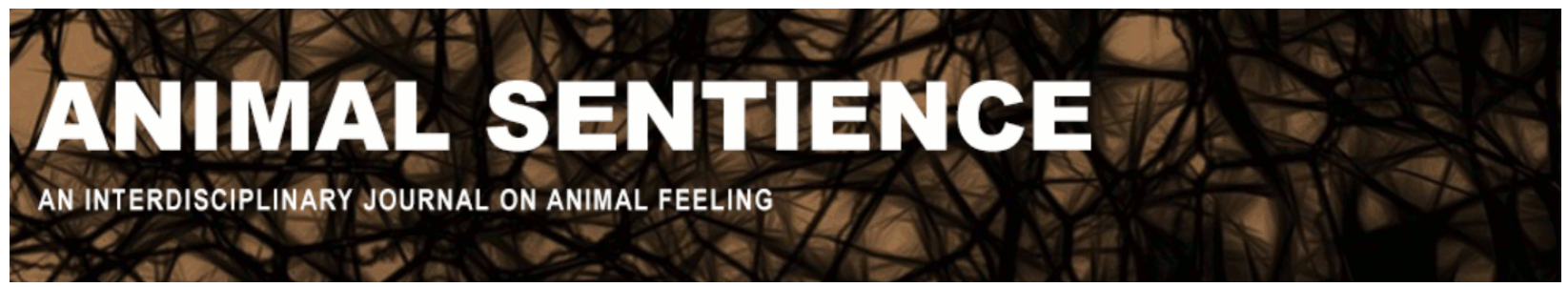

Beauchamp, Guy (2018) The many faces of fear and vigilance. Animal Sentience 15(9)

DOI: $10.51291 / 2377-7478.1361$

Date of submission: 2018-07-31

Date of acceptance: 2018-08-13

(c)

This article has appeared in the journal Animal

Sentience, a peer-reviewed journal on animal

cognition and feeling. It has been made open access,

free for all, by WellBeing International and deposited

in the WBI Studies Repository. For more information,

please contact

wbisr-info@wellbeingintl.org.

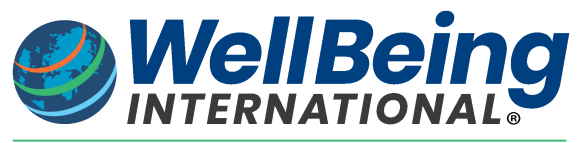

SOLUTIONS FOR PEOPLE, ANIMALS AND ENVIRONMENT 


\title{
The many faces of fear and vigilance
}

Response to Commentary on Beauchamp on Fear \& Vigilance

\author{
Guy Beauchamp \\ Independent Researcher, Canada
}

\begin{abstract}
In the target article, I examined the relationship between vigilance and fear in prey animals. The joint occurrence of vigilance and other physiological responses to fear, such as increased heart rate and stress hormone release, would bolster the idea that vigilance can be a useful marker of fear. Nevertheless, a common theme in much of the empirical research is an uncoupling of vigilance and physiological correlates of fear. The commentators suggest several ways to refine the concepts of vigilance, fear, and risk. I discuss these refinements, which in the end will prove useful to assess further the relationship between vigilance and fear.
\end{abstract}

Guy Beauchamp, Ph.D. in Zoology, University of Cambridge, does independent research in Canada on the evolution of sociality and social foraging strategies, using theoretical modelling, the comparative method, and studies in the field or in the

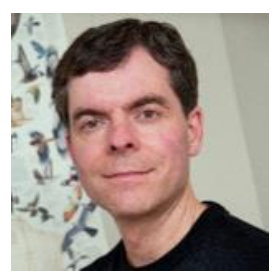
laboratory. Website

I want to thank all the commentators for their thoughtful comments on the target article (Beauchamp, 2017). I organize my reply in four sections, dealing principally with refinements proposed by various commentators on the concepts of fear, vigilance and risk.

\section{Refining Fear}

Vigilance need not be involved in the fear response in all types of situations. In fact, as Adolphs notes, there could be many types or stages of fear, each of which may or may not be associated with vigilance. Vigilance, for instance, would be an impediment in a situation that calls for an immediate escape response. An alternative view is that there is one type of fear, but that vigilance is deployed only under some situations (Adolphs). With either point of view, I agree that vigilance might be a better marker of fear once we can more easily specify the subtype of fear involved or the type of threats.

\section{Refining Vigilance}

In the target article, I suggested that the quality of vigilance is just as important as the total amount of vigilance. Blinking during vigilance, as one example, can interfere with the acquisition of information about threats and would be expected to decrease in a threatening situation (Matsumoto-Oda, Okamoto, Takahashi, \& Ohira, 2018). If responses to threats are 
carried out to a significant extent by adjustments in blinking (or other variables), the association between the total time spent being vigilant and being fearful might be weakened.

Several commentators elaborated on this issue. Rogers discusses the implication of asymmetry of the brain regions involved in the detection and processing of threats. For animals with laterally placed eyes, the left eye, which is associated with the right hemisphere, is typically involved in responses to predator detection. This observation suggests that a better association between vigilance and fear could emerge when taking into account side biases. Previous work on this issue dealt mostly with reactive vigilance (responses to an already detected predator) (Austin \& Rogers, 2012, 2014; Wichman, Freire, \& Rogers, 2009). Pre-emptive surveillance might involve the left rather than the right hemisphere of the brain (and thus be carried out by the right eye) if animals are paying attention to very specific features associated with predators (Rogers, personal communication). These fascinating developments await further testing.

I noted that in some species, individuals maintain consistently high or low vigilance across situations. This is problematic because we expect vigilance to covary directly with the threat level. In some species, some individuals show low vigilance but are able to mount a reaction to increasing risk while others are highly vigilant and less responsive to changes in risk (Found). Pooling individuals with such varied profiles might weaken the relationship between vigilance and fear.

To get better measurements of vigilance, Teichroeb also suggests identifying the target of vigilance as well as possible to eliminate sources of vigilance that are not related to threats. In addition, the context in which vigilance occurs and the intensity of vigilance can tell us about the level of perceived risk. For example, animals may stop chewing (which makes vigilance more costly) when sensing more danger (Lynch et al., 2015). More costly forms of vigilance might be indicative of a greater level of risk and would presumably correlate better with other physiological markers of fear (Mónus; Teichroeb). I concur, but note that distinguishing the target of vigilance is not easy for animals with laterally placed eyes and different forms of vigilance are not always evident.

\section{Refining Risk}

Feyten \& Brown discuss a framework to explore the association between vigilance and fear. This novel and exciting framework includes two major components, namely, predictability of risk (or environmental certainty in broader terms) and the reliability of cues associated with predation risk. The interaction between the two components is crucial to determining whether vigilance and other physiological correlates of fear tend to occur together. I agree, and here I want to add some details.

When predation risk is predictable and reliable cues are available to detect predators, it is true that a chronic physiological response (i.e., active at all times and places) is not needed. Nevertheless, I would argue that high vigilance and a strong physiological response should take place together at the predictably risky times or places. This means it is crucial to determine how predation risk varies in time and space, and to specify when and/or where stress responses and vigilance are documented.

If reliable cues are not available but predation risk is predictable, Feyten \& Brown argued that vigilance should decrease. When cues are very unreliable, vigilance becomes 
ineffective, and I agree that it should decrease (Iribarren \& Kotler, 2012). However, if vigilance maintains some utility, an increase in vigilance might pay off instead. For instance, in response to loud anthropogenic noises that make sound cues less effective, prey can increase visual vigilance to compensate (Klett-Mingo, Pavón, \& Gil, 2016).

One difficulty in general is that prey can take preventive measures to manage predictable or unpredictable risk involving factors other than vigilance or stress responses. This could involve avoiding the risky places or times, or reducing risk in general through behavioural means. Joining a large group, for instance, can lead to a reduction in vigilance (Beauchamp, 2015), and the presence of companions can dampen stress responses despite high risk (Hennessy, Kaiser, \& Sachser, 2009). Although prey probably pay a cost for these choices in terms of food intake, expected changes in vigilance or stress responses might not be as strong as predicted by this framework if alternatives are available. In conclusion, I argue that it is important to consider not only the predictability of risk and cue reliability, but also the availability of alternative options to manage risk.

\section{What's in a Name?}

Kotler \& Brown propose a definition of fear that relies on the predation costs of foraging, which include factors such as the rate of encounter with predators and future reproductive success. I have no quarrel at all with the way predation costs are formulated, nor with the conclusion that under some circumstances, fear as just defined above might not always be associated with vigilance.

I want to raise a semantic issue, namely, the use of the word "fear" when defined in strictly ecological terms. In the ecological framework, fear represents one evocative way to depict the predation costs of foraging. However, few behavioural ecologists have measured the state of fear let alone the feeling of fear in their study subjects. Traditionally, behavioural ecologists are concerned with predicting outcomes using the logic of natural selection, leaving aside considerations about physiological and psychological processes underlying behaviour. It is hence surprising to rely on a term with such a strong association with internal processes.

Fear is a loaded term; for most people, it carries the implication of feeling and of being consciously aware of one's state of fear. Even within the field of psychology, use of the term fear in human and non-human research has been criticized on such grounds (LeDoux, 2014). Teichroeb also stresses the importance of being cautious when attributing fear to study animals. I think terms like fear are best left aside when the goal of the research is to predict outcomes. However, I do not mean to imply that animals cannot fear.

\section{Conclusions}

With the above refinements, I think the path to elucidate the relationship between vigilance and fear is more evident. Work on side biases and personality is likely to remove some confounding factors. Refinements in the measurement of vigilance will also undoubtedly provide a clearer picture. 


\section{References}

Adolphs, R. (2017). Operationalizing fear through understanding vigilance. Animal Sentience 15(2).

Austin, N. P., \& Rogers, L. J. (2012). Limb preferences and lateralization of aggression, reactivity and vigilance in feral horses, Equus caballus. Animal Behaviour, 83, 239-247.

Austin, N. P., \& Rogers, L. J. (2014). Lateralization of agonistic and vigilance responses in Przewalski horses (Equus przewalskii). Applied Animal Behaviour Science, 151, 43-50.

Beauchamp, G. (2015). Animal vigilance: Monitoring predators and competitors. London: Academic Press.

Beauchamp, G. (2017). What can vigilance tell us about fear? Animal Sentience 15(1).

Feyten, L. E. A., \& Brown, G. E. (2018). Ecological uncertainty influences vigilance as a marker of fear. Animal Sentience 15(7).

Found, R. (2017). Individual variation in fear behaviour. Animal Sentience 15(3).

Hennessy, M. B., Kaiser, S., \& Sachser, N. (2009). Social buffering of the stress response: Diversity, mechanisms, and functions. [Review]. Frontiers in Neuroendocrinology, 30, 470-482.

Iribarren, C., \& Kotler, B. P. (2012). Patch use and vigilance behaviour by Nubian ibex: The role of the effectiveness of vigilance. Evolutionary Ecology Research, 14, 223-234.

Klett-Mingo, J. I., Pavón, I., \& Gil, D. (2016). Great tits, Parus major, increase vigilance time and reduce feeding effort during peaks of aircraft noise. Animal Behaviour, 115, 29-34.

Kotler, B. P., \& Brown, J. S. (2017). Fear and loathing on the landscape: What can foraging theory tell us about vigilance and fear? Animal Sentience 15(5).

LeDoux, J. E. (2014). Coming to terms with fear. Proceedings of the National Academy of Sciences, 111, 2871-2878.

Lynch, E., Northrup, J. M., McKenna, M. F., Anderson, C. R., Angeloni, L., \& Wittemyer, G. (2015). Landscape and anthropogenic features influence the use of auditory vigilance by mule deer. Behavioral Ecology, 26, 75-82.

Matsumoto-Oda, A., Okamoto, K., Takahashi, K., \& Ohira, H. (2018). Group size effects on inter-blink interval as an indicator of antipredator vigilance in wild baboons. Scientific Reports, 8, 10062.

Mónus, F. (2018). Competing activities as measures of fear and vigilance. Animal Sentience 15(8).

Rogers, L. J. (2017). Considering side biases in vigilance and fear. Animal Sentience 15(4).

Teichroeb, J. A. (2017). Methodological suggestions for inferring fear from vigilance. Animal Sentience 15(6).

Wichman, A., Freire, R., \& Rogers, L. J. (2009). Light exposure during incubation and social and vigilance behaviour of domestic chicks. Laterality, 14, 381-394. 